\title{
Physician-Assisted Suicide: Against Medical Neutrality
}

\author{
Daniel P. Sulmasy, MD, PhD' , Ilora Finlay, FRCP, FRCGP, FMedSci², Faith Fitzgerald, MD $^{3}$, \\ Kathleen Foley, $M D^{4}$, Richard Payne, $M D^{7}$, and Mark Siegler, $M D^{5}$
}

${ }^{1}$ Kennedy Institute of Ethics, Healy 419, Georgetown University, Washington, DC, USA; ${ }^{2}$ Cardiff University, Cardiff, DC, USA; ${ }^{3}$ UC Davis, Davis, CA, USA; ${ }^{4}$ Emeritus, Memorial Sloan Kettering Cancer Center, New York, NY, USA; ${ }^{5}$ The University of Chicago, Chicago, IL, USA.

J Gen Intern Med 34(8):1372

DOI: $10.1007 / \mathrm{s} 11606-019-05019-1$

(C) Society of General Internal Medicine 2019

$\mathrm{T}_{\mathrm{C}}$ o the Editor:

Clayville and Miller misrepresent our article. We do not argue for the "radical autonomy of physicians," but against the "radical autonomy of patients." Rejecting the latter does not imply the former. Physician autonomy, in our view, is not absolute, but is constrained by the internal morality and rationality of medicine, the common good, and by the particularity and individuality of patients. Pitting the patient against the physician in a contest of competing autonomous wills is exactly the approach that we reject. Medicine is best understood as a joint project undertaken by health care professionals in conjunction with patients towards a shared goal of healing and prevention.

We do argue that all patients have intrinsic value, but this value is not, as Clayville and Miller would characterize it, "subjective." Rather, the intrinsic value of all persons is the bedrock upon which respect for patients and their particular values and preferences rests. It is out of respect for the intrinsic value of the sick that medicine has its moral warrant to provide care in the first place. It is this value, which is anything but subjective, that the legalization of physician-assisted suicide (PAS) subverts.

We agree with Clayville and Miller that hospice care is given in teams and that hospice workers often get to know patients well. However, even if many patients who elect assisted suicide are enrolled in hospice, the fact remains that one in four hospice patients are enrolled for fewer than five days, which is hardly enough time to develop an intimate relationship. ${ }^{1}$ Moreover, PAS is frequently prescribed by physicians who have never met the patient. For example, between 2001 and 2007, 23\% of lethal prescriptions in Oregon were written by just three physicians. ${ }^{2}$ One California physician devotes his entire practice to PAS, belying the idea that PAS

$\overline{\overline{\text { Sadly, our dear colleague Dr. Richard Payne, of Duke University, expired }}}$ after this manuscript was accepted. May he rest in peace.

Published online May 16, 2019 is an extension of long-term, intimate, patient-physician relationships. ${ }^{3}$ Moreover, it is not uncontrolled symptoms, but loss of meaning, loss of independence, being tired of living, and fears of burdening others that drive requests for PAS. ${ }^{4,5}$ Even under ideal conditions, no physician, qua physician, can claim the expertise needed to evaluate such matters and render a judgment that a patient's suffering has become unbearable and warrants death.

It is for these reasons, among others that we detailed in our article, that we hold that PAS has no place in medical practice, that organized medicine ought to continue to oppose its legalization, and that the permissiveness implied by so-called neutrality ought to be rejected.

Corresponding Author: Daniel P. Sulmasy, MD, PhD; Kennedy Institute of Ethics, Healy 419 Georgetown University, Washington, DC, USA (e-mail: sulmasyd@georgetown.edu).

\section{Compliance with Ethical Standards:}

Conflict of Interest: The authors declare that they do not have a conflict of interest.

\section{REFERENCES}

1. Medicare Payment Advisory Commission. March 2017 Report to the Congress: Medicare Payment Policy. Chapter 12: Hospice Services. Vol 2017. Washington D.C.: Medicare Payment Advisory Commission; 2017.

2. Stevens KR. Concentration of Oregon's assisted suicide prescriptions \& deaths from a small number of prescribing physicians. Physicians for Compassionate Care Educational Foundation. March 18, 2015. http:// w w w. p c c e f. or g/res o u r e s/ d o c u m e n t s / ConcentrationofOregonsAssistedSuicideDeaths3182015revision.pdf

3. Beresford L. Berkeley doctor wants to help California patients, hospices with aid-in-dying law. The Lancet USA Health Blog. 2017. http://usa. thelancet.com/blog/2017-02-01-berkeley-doctor-wants-help-californiapatients-hospices-aid-dying-law

4. Ganzini L, Goy ER, Dobscha SK. Why Oregon patients request assisted death: family members' views. J Gen Intern Med 2008;23:154-7.

5. Oregon Public Health Division, "Oregon Death with Dignity Act: Data Summary 2017," Feb. 9, 2018. https://www.oregon.gov/oha/PH/ PROVIDERPARTNERRESOURCES / EVALUATIONRESEARCH / DEATHWITHDIGNITYACT/Documents/year20.pdf

Publisher's Note Springer Nature remains neutral with regard to jurisdictional claims in published maps and institutional affiliations. 